\title{
Professor Samuel C. Brooks, Jr., Ph.D. (1928-2019)
}

\author{
Lisa A. Polin ${ }^{1}$ - Malathy Shekhar ${ }^{1}$
}

Published online: 16 March 2020

(C) Springer Science+Business Media, LLC, part of Springer Nature 2020



It is with a heavy heart that we share with you the passing of Samuel "Sam" Carroll Brooks, Jr., Ph.D., former deputy director, director of Chemistry and chief of Endocrinology at the Barbara Ann Karmanos Cancer Institute and professor of Biochemistry and Molecular Biology at the Wayne State University (WSU) School of Medicine. He died peacefully at the age of 91 at his home in Colorado on December 15, 2019, after a battle with cancer.

Dr. Brooks was widely known for his scientific and scholarly contributions to breast cancer research, working alongside Gloria Heppner, Ph.D. He and another collaborator, Herb Soule, Ph.D., were early pioneers in the development of the MCF-7 cell line, the first human breast cancer cell line ever produced. The cells, derived from a breast cancer patient and developed at the Michigan Cancer Foundation (MCF) in Detroit, Mich., became a standard model for breast cancer research labs around the world. Dr. Brooks, working with Dr. Soule, first described estrogen receptor alpha in MCF-7 cells by both Scatchard and sucrose density gradient analysis.

Lisa A. Polin

polin1@karmanos.org

1 Department of Oncology, Wayne State University School of Medicine, Karmanos Cancer Institute, Detroit, MI, USA
This was a pivotal discovery that characterized the line and was instrumental in recognizing the importance of estrogen receptor and its role in the development of breast cancer. Dr. Brooks was a renowned biomedical scientist also known for his contributions to the understanding of biosynthesis, metabolism, and mode of action of estrogens. He held three patents, and his work was instrumental in developing the clinical assay to determine an individual's hormone receptor status, which was critical to establishing the optimal treatment for breast cancer patients. Dr. Brooks, along with others at MCF, also worked on the development of the MCF-10 cell lines, the first non-transformed human breast cell line and its cancer progression series.

Dr. Brooks retired from WSU and Karmanos in 2005 at the age of 77. He started working for the university and Michigan Cancer Foundation in 1959 and served as director of the MCF Chemistry Department from 1970 to 1974 and as chief of the Endocrinology Laboratory in the Clinical Research Department from 1974 to 1981. In 1978, he was part of the team that established the National Cancer Institutedesignated Meyer L. Prentis Comprehensive Cancer Center of Metropolitan Detroit, the direct predecessor of the Barbara Ann Karmanos Cancer Institute. He served the Comprehensive Cancer Center as an associate director for research from 1982 to 1988, was a Breast Cancer Program leader until 2003, and was a member of the senior leadership from 1988 to 2005.

Concurrent with his responsibilities at MCF, Dr. Brooks held appointments at Wayne State University, where he was a professor of Biochemistry and Molecular Biology (1974) with cross appointments in the departments of Gynecology and Obstetrics (1976), Physiology (1981), and Oncology (1997). During his career at MCF/Karmanos and WSU, he served as an associate editor for Cancer Research from 1980 to 1993 and was on the editorial board for Steroids from 1993 until his retirement in 2005. Dr. Brooks maintained an unbroken string of continuous funding from his first grant in 1968 until his retirement in 2005, one of the longest records of continuous research funding in the university's history. 
Dr. Brooks was an outstanding mentor to numerous graduate and medical students, and junior faculty. He taught many graduate and medical school courses and was the original principal investigator of the WSU T32 NCI Training Grant for the Cancer Biology Graduate Program, serving as its director until his retirement in 2005 . He initiated a similar research training program in breast cancer with Department of Defense funding for undergraduates from 1991 to 1996 . He was named Outstanding Teacher of the Year by the WSU School of Medicine student body and was widely respected by his associates and students. In 1994, he was elected into the
WSU Academy of Scholars, serving as its president in 20002001. He received the School of Medicine Distinguished Service Award in 2000 and Lifetime Achievement Award in 2005.

In addition to his scientific contributions, Dr. Brooks will be fondly remembered for his kindness, sense of humor, knack for storytelling, and his love for animals. Our heartfelt sympathy goes out to his family, friends, and students.

Publisher's note Springer Nature remains neutral with regard to jurisdictional claims in published maps and institutional affiliations. 